\title{
Optimal Ki67 cut-off for luminal breast cancer prognostic evaluation: a large case series study with a long-term follow-up
}

\author{
Sara Bustreo ${ }^{2} \cdot$ Simona Osella-Abate $^{1} \cdot$ Paola Cassoni $^{1} \cdot$ Michela Donadio $^{2} \cdot$ \\ Mario Airoldi ${ }^{3}$ Fulvia Pedani ${ }^{3} \cdot$ Mauro Papotti $^{4} \cdot$ Anna Sapino $^{1,5}$. \\ Isabella Castellano ${ }^{1}$
}

Received: 14 March 2016/Accepted: 26 April 2016/Published online: 7 May 2016

(c) The Author(s) 2016. This article is published with open access at Springerlink.com

\begin{abstract}
Although Ki67 index suffers from poor reproducibility, it is one of the most important prognostic markers used by oncologists to select the treatment of estrogen receptor (ER) positive breast cancer patients. In this study, we aim to establish the optimal Ki67 cut-offs for stratifying patient prognosis and to create a comprehensive prognostic index for clinical applications. A mono-institutional cohort of 1.577 human epidermal growth factor receptor 2 negative/ER+ breast cancer patients having complete clinical, histological, and follow-up data was collected. The 14 and $20 \%$ Ki67 cut-offs were correlated to disease-free interval (DFI) and disease-specific survival (DSS). To create a comprehensive prognostic index, we used independent variables selected by uni/multivariate analyses. In terms of DFI and DSS, patients bearing tumors with Ki67 $<14 \%$ proliferation index did not differ from those with Ki67 values between 14 and $20 \%$. Patients with tumor with Ki67 $>20 \%$ showed the poorest prognosis. Moreover, to tumor size, the number of metastatic lymph
\end{abstract}

Sara Bustreo and Simona Osella-Abate have contributed equally to this work.

Isabella Castellano

isabella.castellano@unito.it

1 Division of Pathology, Department of Medical Sciences, University of Torino, Via Santena 7, 10126 Turin, Italy

2 Department of Medical Oncology 1, Città della Salute e della Scienza Hospital, Turin, Italy

3 Department of Medical Oncology 2, Città della Salute e della Scienza Hospital, Turin, Italy

4 Department of Oncology, University of Torino, Turin, Italy

5 Pathology Unit, Fondazione del Piemonte per l'Oncologia (FPO), Candiolo Cancer Institute (IRCCS), Candiolo, Italy nodes and Ki67 > $20 \%$ was given a score value, varying depending on definite cut-offs and used to create a prognostic index, which was applied to the population. Patients with a prognostic index $\geq 3$ were characterized by significant risk of relapse [DFI: Hazard Ratio $(\mathrm{HR})=4.74$, $p<0.001]$ and death (DSS: HR $=5.03, p<0.001$ ). We confirm that the $20 \%$ Ki67 cut-off is the best to stratify high-risk patients in luminal breast cancers, and we suggest to integrate it with other prognostic factors, to better stratify patients at risk of adverse outcome.

Keywords Ki67 cut-offs · Prognostic index · Luminal breast cancer - Relapse

$\begin{array}{ll}\text { Abbreviations } \\ \text { ER } & \text { Estrogen receptor } \\ \text { HER2 } & \text { Human epidermal growth factor receptor 2 } \\ \text { DFI } & \text { Disease-free interval } \\ \text { DSS } & \text { Disease-specific survival } \\ \text { PR } & \text { Progesterone receptor } \\ \text { AIC } & \text { Akaike information criterion } \\ \text { NCCN } & \text { National comprehensive cancer network }\end{array}$

\section{Introduction}

The immunohistochemical surrogate of molecular subclasses of breast cancers proposed by the Saint Gallen Consensus Meetings [1-3] is largely used to classify patients in different risk categories. However, the main drawback of this classification is the low consistency in classifying Luminal A and Luminal B/HER2-negative (HER2-) carcinomas. Actually, both of them are estrogen 
receptor positive (ER+) and HER2-, but Luminal B category should identify patients with worse prognosis, endorsed for chemotherapy in addition to hormone blockage. Therefore, to differentiate Luminal A from Luminal B/HER2 - breast cancers carries important therapeutic implications. For this aim, the Saint Gallen Guidelines [1] recommend to assess the proliferation index by Ki67, a nuclear marker of cell proliferation that is expressed in all cell cycle phases, except G0 [4]. A Luminal B breast cancer should show a higher proliferation index than Luminal A; however, the Ki67 cut-off for differentiating these two categories changed over time. The 2011 Saint Gallen Consensus Meeting defined as "low proliferation" tumors with a Ki67 index $<14 \%$ [3], a cut-off established by comparison with PAM50 intrinsic multigene molecular test classification of Luminal cancers [5]. Otherwise, during the 2013 Saint Gallen Conference, the majority of panelists voted that a threshold of $\geq 20 \%$ was indicative of "high" Ki67 status. At the same time, several works reported low reproducibility of Ki67 results, mainly in the subset of cancers with intermediate proliferation activity (between 15 and $30 \%$ ) [6-10]. Thus, in March 2015, during the last Saint Gallen Conference [1], the use of the median Ki67 value of local laboratory was proposed as the cut-off, and accepted by the panel of experts.

In our Institution, the median Ki67 value (tested on 547 consecutive luminal invasive breast cancers, operated between January and December 2014) is $14 \%$. Thus, we analyzed a large retrospective cohort of Luminal $\mathrm{ER}+$ / HER2 - breast cancers, with long follow-up, with the following aims: (1) to establish which is the optimal Ki67 cutoff (14 vs $20 \%$ ) to stratify cases according to disease-free interval (DFI) and disease-specific survival (DSS) at 5 and 10 years, and (2) to assess the prognostic significance of intermediate Ki67 values. In addition, considering that patient prognosis depends on tumor and patient characteristics, we investigated the role of proliferation activity within a comprehensive prognostic index, which uses independent variables to stratify patients having "good" or "poor" prognosis.

\section{Patients and methods}

\section{Study design and population}

We investigated 1688 female patients with ER+/HER2primary breast cancers who underwent surgery from June 1994 to December 2012 at the Breast Unit of the Città della Salute e della Scienza of Torino, University Hospital of Torino, Italy. Ethical approval for this study was obtained from the Ethical Committee of our Institution.
The following clinico-pathological data were obtained from clinical charts: age at diagnosis, type of surgery (conservative surgery vs radical mastectomy), therapy, type, and site of recurrence. In addition, data regarding size ( $<15 \mathrm{vs} \geq 15 \mathrm{~mm}$ ), histological type and grade of tumor, nodal involvement, vascular invasion, Progesterone Receptor (PR), ER, HER2, and Ki-67 was obtained from pathological reports. In particular, for what concerns Ki67, we set cut-points at $14 \%$ (low) and $20 \%$ (high), and of PR at $20 \%$ as recommended by St. Gallen experts [2, 3]. Complete clinical and histopathological data were available for 1577 out 688 patients.

\section{Statistical analyses}

Pearson's Chi-square test and Student's $t$ test were preliminary performed to compare categorical and continuous variables, respectively, and to evaluate potential differences in the variable distribution among groups. The disease-free interval (DFI) was calculated from the date of surgical excision of the primary tumor to the date of the first relapse or last check-up. Disease-specific survival (DSS) was calculated from the surgical excision date of the primary tumor to the date of breast cancer death or last check-up. Survival distribution curves were plotted using the Kaplan-Meyer method, and the statistical comparisons were performed using the log-rank test. Cox regression analyses were carried out on DFI and DSS to calculate crude and adjusted HRs and $95 \%$ CIs for the different study group. Cases lost to follow-up and cases with a nonbreast cancer related deaths were censored at the last follow-up control. A model was created for evaluating the prognostic role of different variables. The proportional hazard assumption was assessed with the Schoenfeld residuals. This did not give reasons to suspect violation of this assumption. The nature of variables (continue/categorical) included in the model was evaluated considering literature reports and the results of the log-likelihood ratio test. Akaike information criterion (AIC) was used for model selection. All statistical tests were two sided. $p$ values $<0.05$ were considered significant. Statistical analyses were performed using Stata/SE12.0 Statistical Software (STATA, College Station, TX).

\section{Results}

The characteristics of the 1688 patients with ER+/HER2breast cancer stratified according to Ki67 cut-offs are reported in Tables 1 and 2. DFI and DSS were evaluated in patients with low $(<14 \%)$, intermediate $(14-19 \%)$ and high $(\geq 20 \%)$ Ki67 levels. Patients affected by cancers 
Table 1 The characteristics of the 1688 patients with ER+/HER2 - breast cancer stratified according to Ki67 cut-offs

\begin{tabular}{|c|c|c|c|c|c|c|c|}
\hline & Total & Ki67 $<14 \%$ & $\mathrm{Ki} 67 \geq 14 \%$ & $\mathrm{p}$ & Ki67 $<20 \%$ & $\mathrm{Ki} 67 \geq 20 \%$ & $p$ \\
\hline \multicolumn{8}{|l|}{ Age at diagnosis } \\
\hline Median, interval & $62(23-92)$ & $62(34-87)$ & $62(23-92)$ & 0.674 & $62(23-92)$ & $61(27-88)$ & 0.141 \\
\hline \multicolumn{8}{|c|}{ LN metastatic $(n)$ (missing 5) } \\
\hline 0 & 1133 & 596 & 537 & \multirow[t]{4}{*}{$<0.001$} & 834 & 299 & \multirow[t]{4}{*}{$<0.001$} \\
\hline $1-3$ & 405 & 177 & 228 & & 249 & 156 & \\
\hline $4-9$ & 96 & 34 & 62 & & 48 & 48 & \\
\hline$>9$ & 49 & 14 & 35 & & 18 & 31 & \\
\hline \multicolumn{8}{|c|}{ Tumor size (mm) (missing 58) } \\
\hline$<15$ & 912 & 527 & 385 & \multirow[t]{2}{*}{$<0.001$} & 717 & 195 & \multirow[t]{2}{*}{$<0.001$} \\
\hline$\geq 15$ & 718 & 277 & 441 & & 409 & 309 & \\
\hline \multicolumn{8}{|c|}{ Tumor grade (missing 1) } \\
\hline 1 & 634 & 462 & 172 & \multirow[t]{3}{*}{$<0.001$} & 564 & 70 & \multirow[t]{3}{*}{$<0.001$} \\
\hline 2 & 806 & 333 & 473 & & 534 & 272 & \\
\hline 3 & 247 & 27 & 220 & & 53 & 194 & \\
\hline \multicolumn{8}{|c|}{ Vascular invasion (missing 13) } \\
\hline No & 1104 & 637 & 467 & \multirow[t]{2}{*}{$<0.001$} & 858 & 246 & \multirow[t]{2}{*}{$<0.001$} \\
\hline $\mathrm{Si}$ & 571 & 178 & 393 & & 283 & 288 & \\
\hline \multicolumn{8}{|l|}{ PgR\% (missing 111) } \\
\hline$<20 \%$ & 337 & 151 & 186 & \multirow[t]{2}{*}{0.023} & 212 & 125 & \multirow[t]{2}{*}{$<0.001$} \\
\hline$\geq 20 \%$ & 1,240 & 642 & 598 & & 891 & 349 & \\
\hline \multicolumn{8}{|c|}{ Histotype (missing 138) } \\
\hline DC & 961 & 420 & 541 & \multirow[t]{4}{*}{$<0.001$} & 608 & 353 & \multirow[t]{4}{*}{$<0.001$} \\
\hline ILC & 198 & 134 & 332 & & 253 & 79 & \\
\hline IDC + ILC & 157 & 63 & 94 & & 94 & 63 & \\
\hline other & 234 & 139 & 95 & & 194 & 40 & \\
\hline \multicolumn{8}{|l|}{ Surgery (missing 5) } \\
\hline Conservative & 1180 & 608 & 572 & \multirow[t]{2}{*}{$<0.001$} & 655 & 447 & \multirow[t]{2}{*}{$<0.001$} \\
\hline Mastectomy & 503 & 213 & 290 & & 234 & 236 & \\
\hline \multicolumn{8}{|c|}{ Radiotherapy (missing 1) } \\
\hline No & 462 & 196 & 266 & \multirow[t]{2}{*}{$<0.001$} & 282 & 180 & \multirow[t]{2}{*}{$<0.001$} \\
\hline Yes & 1215 & 624 & 591 & & 862 & 353 & \\
\hline \multicolumn{8}{|l|}{ Site of progression } \\
\hline Contralateral & 16 & 7 & 9 & \multirow[t]{3}{*}{0.329} & 8 & 8 & 0.483 \\
\hline Regional & 51 & 13 & 38 & & 17 & 34 & \\
\hline Distant & 94 & 25 & 69 & & 36 & 58 & \\
\hline
\end{tabular}

with low and intermediate Ki67 values had similar DFI and DSS, whereas patients with high Ki67 proliferation index had lower DFI and DSS than patients in the two former groups (Log-rank test DFI $p<0.001$; DSS $p<0.001$ ), Fig. 1.

Univariate Cox analyses estimates reported in Table 2 showed that tumor size $\geq 15 \mathrm{~mm}$, nodal involvement, high grade, and vascular invasion negatively impact on DFI and DSS, together with a high-Ki67 index. As expected, cancers having such features were treated with more aggressive surgery and radiotherapy (Table 1). PR $>20 \%$ failed to play a favorable prognostic role on DSS (Table 3).
Multivariable analyses (Table 4) were performed on 1577 patients with complete clinical and histopathological data. The proportionality assumption was satisfied both on DFI $(p=0.6469)$ and DSS $(p=0.8008)$. Tumor size $\geq 15 \mathrm{~mm}$, nodal involvement, $20 \% \mathrm{Ki67}$ cut-point maintained an unfavorable role on DFI and DSS.

To create a comprehensive index associated to "good" and "poor" prognosis and based on multivariate analysis, a score was attributed to each significant variable according to its HR. Thus, a score value of 1 was given to tumors $>15 \mathrm{~mm}$ and tumors with $\mathrm{Ki67} \geq 20 \%$, whereas a score 0 was given to tumors $\leq 15 \mathrm{~mm}$ and tumors with Ki67 $<20 \%$. Four score 
values were used for lymph nodes ( 0 : lymph nodes free of metastases; 1 : from 1 to 3 metastatic lymph nodes, 2: from 4 to 9 metastatic lymph nodes; 3 : more than 9 metastatic lymph nodes). The comprehensive prognostic index was created

Table 2 Classification on the basis of Ki67 and PgR values

\begin{tabular}{|c|c|c|c|c|}
\hline \multicolumn{2}{|l|}{ ER+ } & $\begin{array}{l}\text { Luminal A } \\
\text { (Ki67 low, } \\
\text { PgR high) }\end{array}$ & \multicolumn{2}{|c|}{$\begin{array}{l}\text { Luminal } \mathrm{B} \\
\text { (Ki67 high or PgR } \\
\text { negative/low) }\end{array}$} \\
\hline \multicolumn{5}{|l|}{ Ki67 } \\
\hline$<14 \%$ & \multicolumn{2}{|c|}{642} & \multicolumn{2}{|l|}{151} \\
\hline$\geq 14 \%$ & \multicolumn{2}{|c|}{-} & \multicolumn{2}{|l|}{784} \\
\hline \multicolumn{5}{|l|}{ Ki67 } \\
\hline$<20 \%$ & \multicolumn{2}{|c|}{891} & \multicolumn{2}{|l|}{212} \\
\hline$\geq 20 \%$ & \multicolumn{2}{|c|}{-} & \multicolumn{2}{|l|}{474} \\
\hline \multicolumn{2}{|c|}{$\mathrm{Ki} 67 \geq 20 \%$} & Luminal $A$ & & Luminal B \\
\hline \multicolumn{5}{|l|}{ Ki67 (\%) } \\
\hline \multicolumn{2}{|l|}{$<14$} & 642 & \multicolumn{2}{|r|}{151} \\
\hline \multicolumn{2}{|l|}{$14-19$} & 249 & \multicolumn{2}{|r|}{61} \\
\hline$\geq 20$ & \multicolumn{2}{|r|}{-} & \multicolumn{2}{|r|}{474} \\
\hline \multirow[t]{2}{*}{ Ki67 (\%) } & \multicolumn{2}{|c|}{$\operatorname{PgR} \%<20 \%$} & \multicolumn{2}{|c|}{$\operatorname{PgR} \% \geq 20 \%$} \\
\hline & Luminal A & Luminal B & Luminal A & Luminal B \\
\hline$<14$ & - & 151 & 642 & - \\
\hline $14-19$ & - & 61 & 249 & - \\
\hline$\geq 20$ & - & 125 & 0 & 349 \\
\hline
\end{tabular}

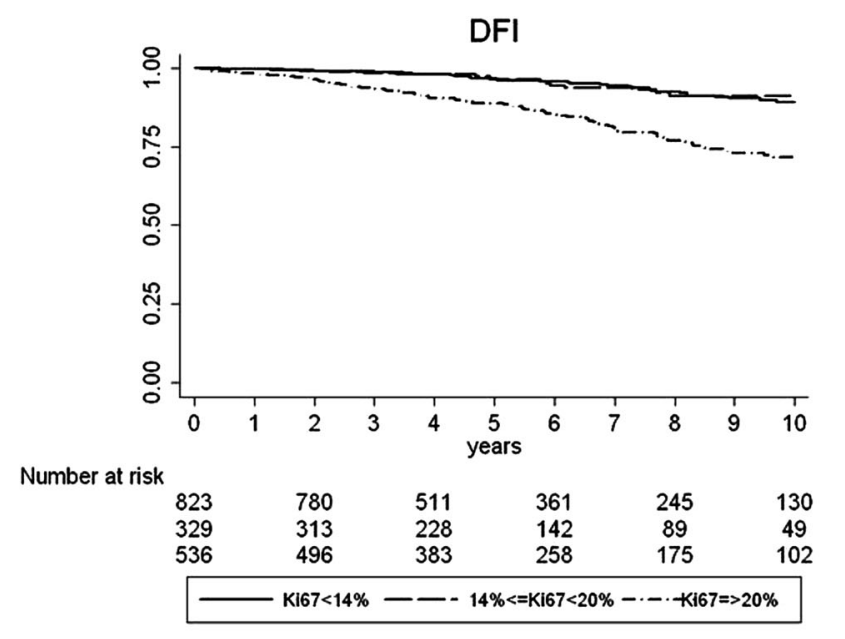

using the following formula: (tumor size score value $)+$ (number of metastatic lymph nodes score value) + (Ki67 score value), determining a range of $0-5$. Kaplan Maier analysis was then carried out for each value. We found that 575 had a final index of $0 ; 481$ of $1 ; 303$ of 2, 147 of 3, 40 of 4, and 21 of 5 . Following the performance curves, we set the index cut-off at 3 , indicating $<3$ a good prognosis and $\geq 3$ a poor prognosis. Patients with an index $\geq 3$ had a significant increased risk of relapse (DFI: $\mathrm{HR}=4.74$, CI 3.46-6.51, $p<0.001$ ) and of death (DSS: $\mathrm{HR}=5.03$, CI 3.19-7.94, $p<0.001)$ Fig. 2.

We then analyzed the outcome of patients according to treatment (1040 hormonal therapy alone; 451 chemotherapy followed by hormone therapy). Eighty-six patients were not treated (comorbidities, older age, therapy refused) and were thus excluded from further analyses. Treatment type did not change DFI and DSS of patients with a score $<3$ (good prognosis) Fig. 3. On the contrary, patients with poor prognosis (score $\geq 3$ ) treated with hormonal therapy alone had a DSS disadvantage, compared to patients treated with adjuvant chemotherapy before hormonal treatment Fig. 4.

\section{Discussion}

The first result of our study is that Luminal breast cancer patients with low $(<14 \%)$ and intermediate $(14-19 \%)$ Ki67 have the same DFI and DSS and a better prognosis

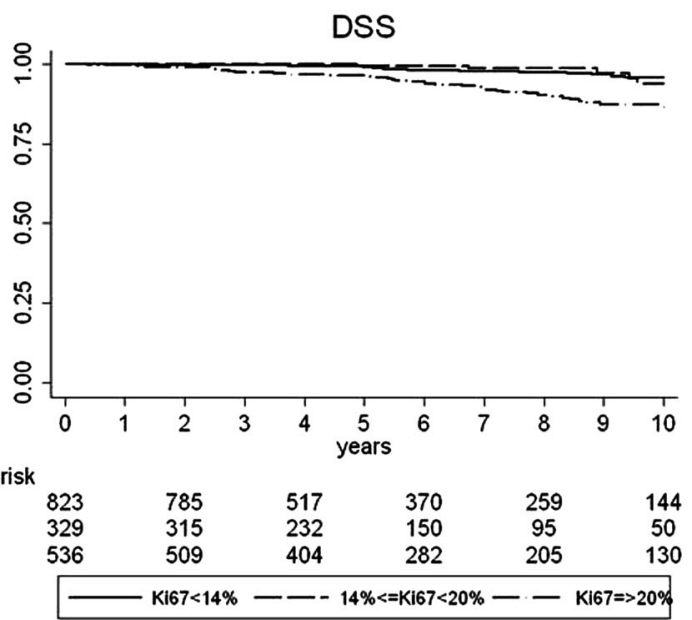

\begin{tabular}{|c|c|c|c|c|c|c|c|c|}
\hline & \multicolumn{4}{|c|}{ DFI } & \multicolumn{4}{|c|}{ DSS } \\
\hline & \multicolumn{4}{|c|}{$\mathrm{Ki} 67$} & \multicolumn{4}{|c|}{$\mathrm{Ki} 67$} \\
\hline & $<14 \%$ & $14 \%-19 \%$ & $\geq 20 \%$ & $\mathrm{p}$ & $<14 \%$ & $14 \%-19 \%$ & $\geq 20 \%$ & $\mathrm{p}$ \\
\hline 5-years & 95.8 & 94.8 & 85.3 & \multirow{2}{*}{$<0.001$} & 98.2 & 99.5 & 94.6 & \multirow{2}{*}{$<0.001$} \\
\hline 10 -years & 88.5 & 91.3 & 71.2 & & 94.8 & 94.2 & 84.5 & \\
\hline
\end{tabular}

Fig. 1 DFI and DSS in low, intermediate, and high Ki67 patients 
Table 3 Univariate analyses on DFI and DSS

\begin{tabular}{|c|c|c|c|c|c|c|}
\hline \multirow[t]{2}{*}{ Variable } & \multicolumn{3}{|l|}{ DFI } & \multicolumn{3}{|l|}{ DSS } \\
\hline & HR & $\mathrm{CI}$ & $p$ & HR & CI & $p$ \\
\hline $\mathrm{Ki} 67 \geq 14 \%$ & 2.33 & $1.65-3.29$ & $<0.001$ & 2.53 & $1.50-4.26$ & $<0.001$ \\
\hline $\mathrm{Ki} 67 \geq 20 \%$ & 3.24 & $2.35-4.45$ & $<0.001$ & 3.77 & $2.32-6.13$ & $<0.001$ \\
\hline \multicolumn{7}{|l|}{ Ki67 \% } \\
\hline$<14 \%$ & 1 & & & 1 & & \\
\hline $14-20 \%$ & 0.90 & $0.51-1.59$ & 0.710 & 0.68 & $0.26-1.83$ & 0.454 \\
\hline$\geq 20 \%$ & 3.14 & $2.21-4.47$ & $<0.001$ & 3.44 & $2.03-5.84$ & $<0.001$ \\
\hline $\operatorname{PgR} \geq 20 \%$ & 0.67 & $0.47-0.95$ & 0.026 & 0.65 & $0.39-1.10$ & 0.107 \\
\hline Mastectomy versus conservative surgery & 3.70 & $2.71-5.07$ & $<0.001$ & 3.87 & $2.44-6.15$ & $<0.001$ \\
\hline \multicolumn{7}{|l|}{ LN metastatic } \\
\hline No & 1 & & & & & \\
\hline N1 & 1.88 & $1.30-2.74$ & 0.001 & 1.36 & $0.76-2.45$ & 0.303 \\
\hline $\mathrm{N} 2$ & 4.78 & $3.03-7.56$ & $<0.001$ & 4.91 & $2.63-9.20$ & $<0.001$ \\
\hline $\mathrm{N} 3$ & 7.34 & $4.41-12.2$ & $<0.001$ & 6.75 & $3.32-13.7$ & $<0.001$ \\
\hline Tumor size $\geq 15$ & 3.62 & $2.52-5.21$ & $<0.001$ & 4.24 & $2.45-7.35$ & $<0.001$ \\
\hline \multicolumn{7}{|l|}{ Tumor grade } \\
\hline 1 & 1 & & & 1 & & \\
\hline 2 & 1.94 & $1.28-2.95$ & 0.002 & 1.92 & $1.00-3.67$ & 0.048 \\
\hline 3 & 3.95 & $2.53-6.16$ & $<0.001$ & 5.00 & $2.61-9.57$ & $<0.001$ \\
\hline Vascular invasion & 2.71 & $1.98-3.71$ & $<0.001$ & 3.00 & $1.87-4.82$ & $<0.001$ \\
\hline \multicolumn{7}{|l|}{ Histotype } \\
\hline IDC & 1 & & & 1 & & \\
\hline ILC & 1.02 & $0.69-1.51$ & 0.906 & 1.17 & $0.68-2.01$ & 0.577 \\
\hline IDC + ILC & 0.79 & $0.47-1.36$ & 0.413 & 0.657 & $0.29-1.47$ & 0.302 \\
\hline Other & 0.72 & $0.43-1.19$ & 0.197 & 0.707 & $0.33-1.49$ & 0.358 \\
\hline Radiotherapy & 0.36 & $0.28-0.49$ & $<0.001$ & 0.44 & $0.28-0.71$ & 0.001 \\
\hline
\end{tabular}

\begin{tabular}{|c|c|c|c|c|c|c|}
\hline \multirow[t]{2}{*}{ Variable } & \multicolumn{3}{|l|}{ DFI } & \multicolumn{3}{|l|}{ DSS } \\
\hline & HR & $\mathrm{CI}$ & $p$ & HR & $\mathrm{CI}$ & $p$ \\
\hline Age at diagnosis & 0.99 & $0.97-1.00$ & 0.355 & 1.00 & $0.98-1.03$ & 0.549 \\
\hline Tumor size $\geq 15$ & 2.06 & $1.35-3.14$ & 0.001 & 2.78 & $1.42-5.41$ & 0.003 \\
\hline Vascular Invasion & 1.14 & $0.76-1.73$ & 0.522 & 1.62 & $0.86-3.05$ & 0.138 \\
\hline $\mathrm{PgR} \geq 20 \%$ & 0.70 & $0.47-1.02$ & 0.066 & 0.66 & $0.38-1.16$ & 0.153 \\
\hline \multicolumn{7}{|l|}{ Metastatic LN } \\
\hline No & 1 & & & 1 & & \\
\hline N1 & 1.53 & $0.98-2.40$ & 0.061 & 1.13 & $0.57-2.26$ & 0.724 \\
\hline $\mathrm{N} 2$ & 3.03 & $1.69-5.44$ & 0.000 & 2.89 & $1.29-6.47$ & 0.010 \\
\hline $\mathrm{N} 3$ & 4.11 & $2.19-7.67$ & 0.000 & 3.41 & $1.43-8.12$ & 0.006 \\
\hline \multicolumn{7}{|l|}{ Tumor grade } \\
\hline 1 & 1 & & & 1 & & \\
\hline 2 & 1.15 & $0.71-1.88$ & 0.569 & 1.10 & $0.51-2.36$ & 0.806 \\
\hline 3 & 1.06 & $0.59-1.89$ & 0.851 & 1.09 & $0.46-2.58$ & 0.836 \\
\hline $\mathrm{Ki} 67 \geq 20 \%$ & 2.35 & $1.56-3.55$ & 0.000 & 2.37 & $1.26-4.47$ & 0.008 \\
\hline
\end{tabular}

Global test DFI $p=0.6429$; DSS $p=0.8008$
Table 4 Multivariate analyses on DFI and DSS 


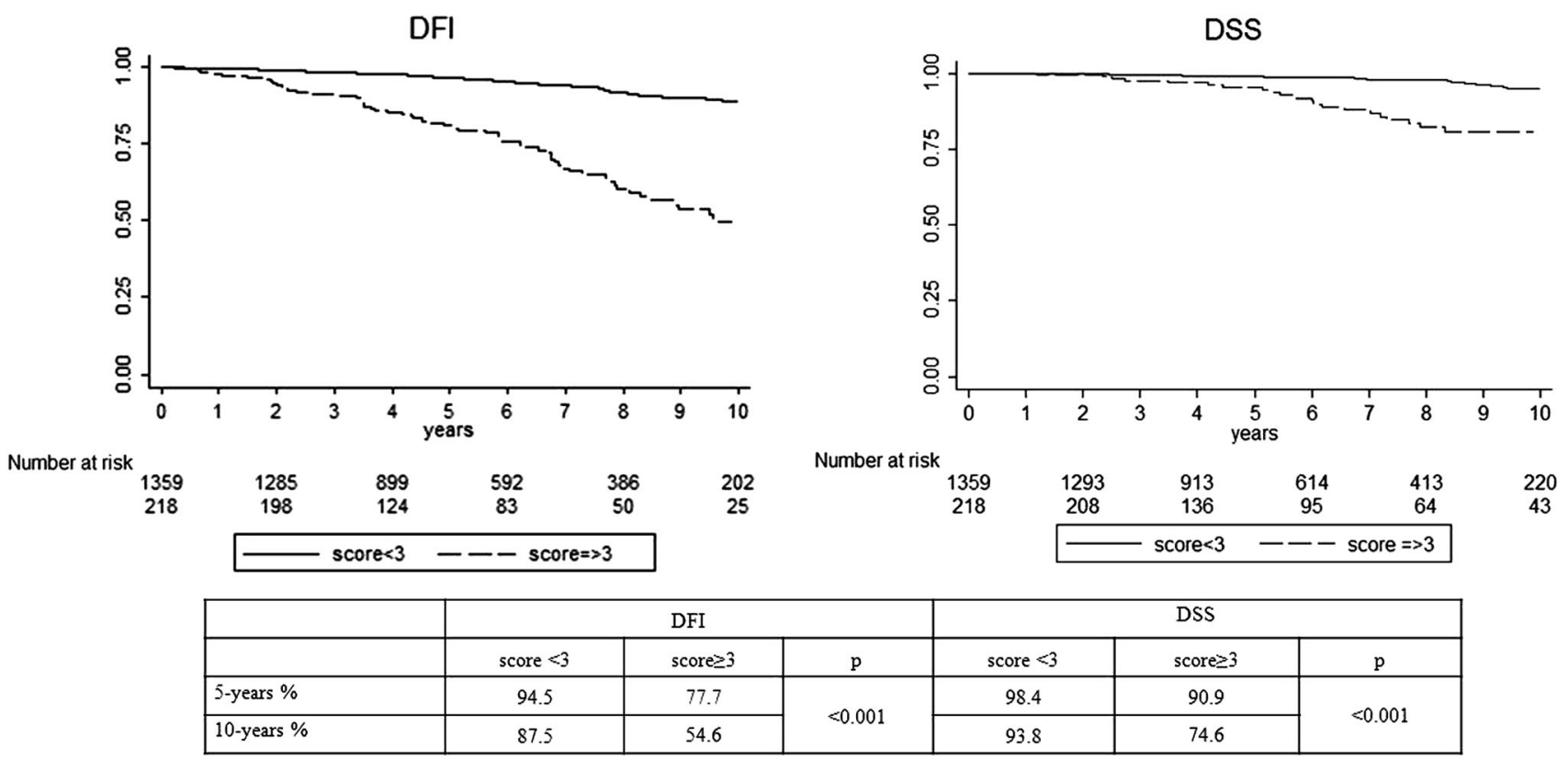

Fig. 2 DFI and DSS in patients stratified on the basis of $\operatorname{good}(<3)$ or poor $(\geq 3)$ score

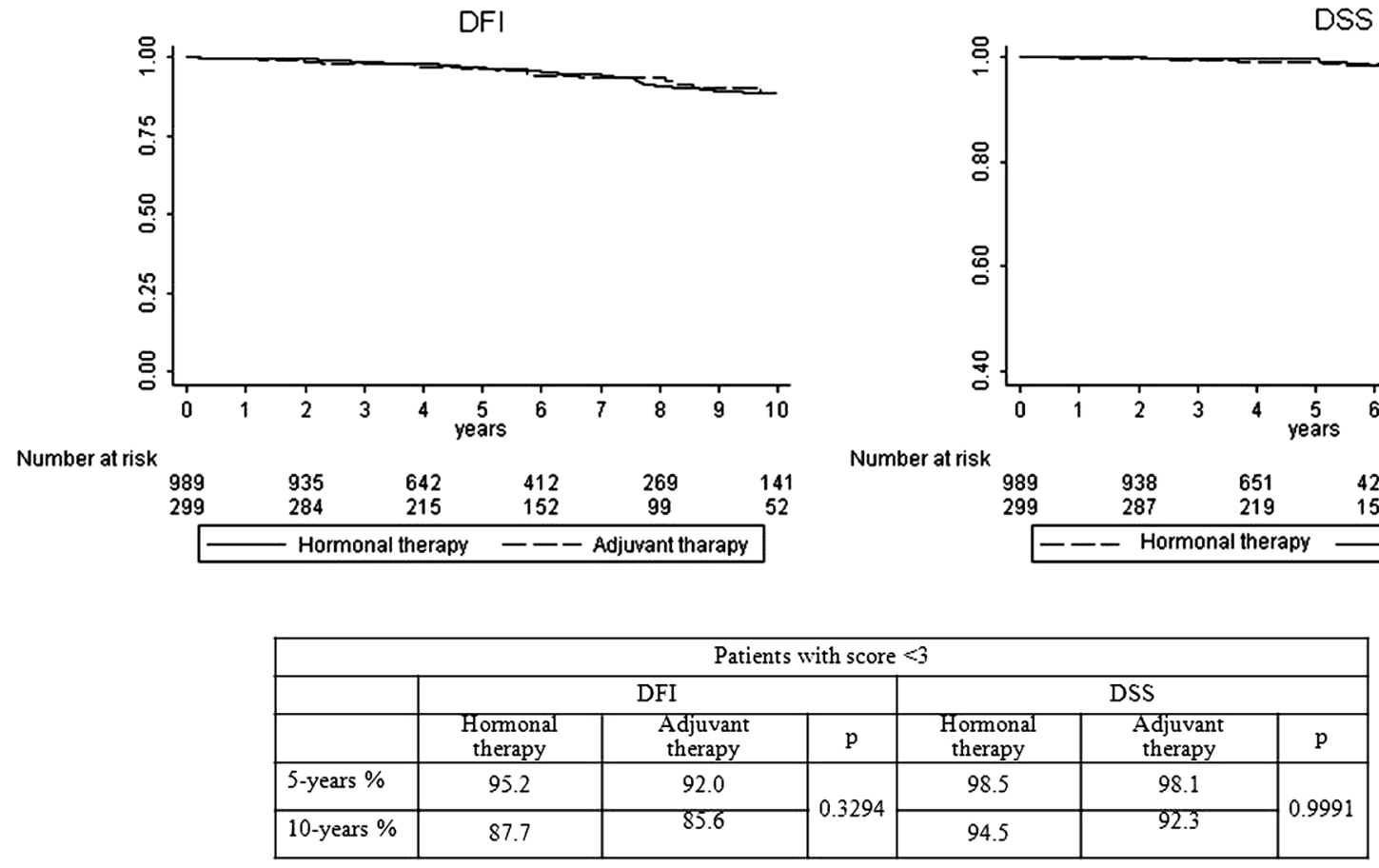

Fig. 3 DFI and DSS in patients with good score $(<3)$ stratified on the basis of therapy

than patients with high ( $\geq 20 \%)$ Ki67. This result confirms that, within ER+/HER2 - breast cancers, the $20 \%$ Ki67 cut-off can reliably (1) discriminate patients at low or high risk of recurrence and death, and (2) stratify patients at higher risk, eligible to adjuvant chemotherapy before hormone therapy.
The usefulness of Ki67 for decision on breast cancer management is a matter of discussion. A number of oncologists advise not to rely on Ki67 in the clinical practice, because of its low reproducibility [2-11]. Additionally, the American National Comprehensive Cancer Network (NCCN) guidelines do not provide any 


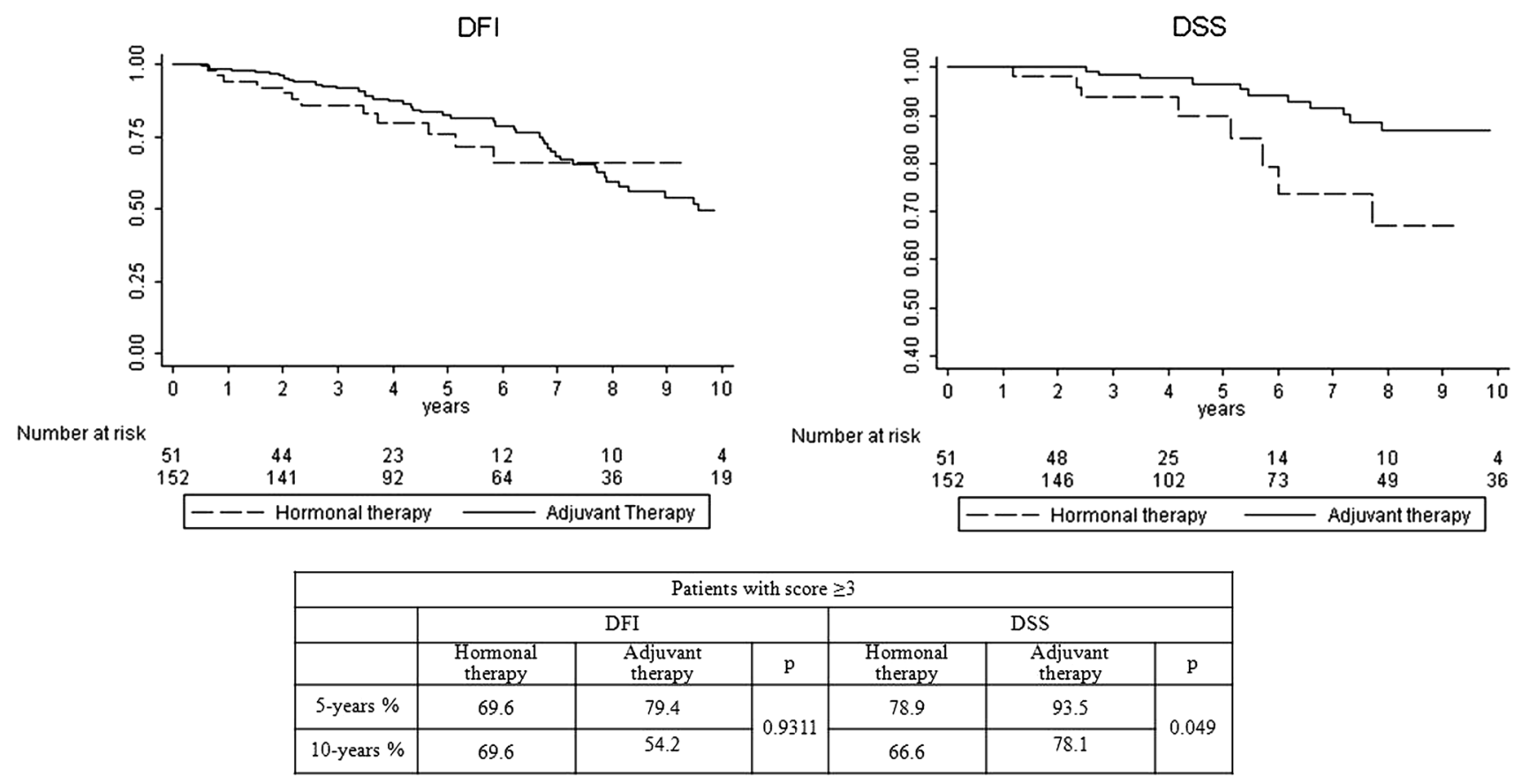

Fig. 4 DFI and DSS in patients with poor score $(\geq 3)$ stratified on the basis of therapy

information regarding Ki67 immunohistochemical assessment and its role in breast cancer prognosis [12].

However, in Europe, the Saint Gallen Consensus Meeting had suggested to use Ki67 for classifying Luminal cancers since 2009. Still, uncertainty regarding the definition of highly proliferating tumors remains. In 2011, a cutoff of $14 \%$ [3] was proposed, on the basis of the study by Cheang et al. [5], but 2 years later, it was upgraded to $20 \%$ [2]. In the same year, Denkert et al. [13] proposed to considered Ki67 a continuum variable and suggested that the cut-points are context dependent and may change according to the prognostic or predictive role given to Ki67 itself. Thus, they suggested that the scientific community could define Ki67 cut-points depending on the study purpose [14]. To solve the literature ambiguities, we evaluated Ki67 in a subset of patients with ER+ (Luminal) breast cancer, with the aim to verify its impact on prognosis. First of all, we calculated the median value of Ki67 in our case series, as suggested by the last Saint Gallen Consensus Meeting [1] and showed that it corresponded to the value of $14 \%$ identified by Cheang [5] as able to discriminate Luminal A from Luminal B molecular subtypes. Patients with a low $(<14 \%)$ and intermediate (14-19\%) Ki67 value showed a better DFI and DSS than those with higher Ki67 ( $\geq 20 \%)$. As a consequence, when the purpose is to recognize high-risk patients, the $20 \%$ cut-off is more reliable and reproducible than the $14 \%$ cut-off. Moreover, Cserni et al. [15] showed that, in the routine practice, the proportion of Ki67 positive cells "tends to cluster around values ending with 5 or 0 ," and accordingly, they proposed to select cut-off values ending with one of these two numbers.

Although we confirm that Ki67 is a reliable marker for identifying patients at low and high risk of recurrences/ death, we firmly believe that Ki67 percentage has to be assessed following International Guidelines [16] and that the laboratory should be strictly subjected to local and external quality control assurance [17].

Moreover, in line with several studies suggesting that one marker is not sufficient to stratify prognosis of breast cancer patients, we designed a comprehensive prognostic index combining Ki67 with tumor size and number of metastatic lymph nodes. This index was highly predictive of DSS and DFI, at both uni- and multivariate analyses, confirming that tumor burden and proliferative index remain the most important parameters in ER+ breast cancer prognosis, as suggested by several other studies [18-22]. Actually, both tumor size and the number of positive axillary lymph nodes are traditionally accepted as important prognostic factors in breast cancer patients [23, 24], and molecular tools such as Endopredict ${ }^{\circledR}$ and PAM50 ${ }^{\circledR}$ include these parameters, in association with specific gene expression, to create a recurrence score called EPclin $^{\circledR}$ and Prosigna ${ }^{\circledR}$ ROR score, respectively. Since a number of genes in these assays are related to proliferative index and to ER pathway, we can reasonably suggest that the use of our prognostic index in Luminal cancer could "surrogate" the multigene prognostic test results. 
In addition, we found that, within the subset of patients with a poor prognostic index $(\geq 3)$, those treated with hormonal therapy alone showed a poorer DSS than those receiving also adjuvant chemotherapy. This result suggests that our prognostic index may be useful to identify patients that need a more aggressive treatment.

Although our study is based on a retrospective and a monocentric dataset of patients, which could represent possible biases, in our Institute, two different pathologists, skilled in breast pathology, assess Ki67 expression, and treatment is decided during multidisciplinary meetings, allowing for discussion among different clinicians.

In conclusion, we confirm the reliability of Ki67 as a prognostic marker in Luminal breast cancers, using a cutoff value of $20 \%$, and we stress the important role of Ki67 in the clinical management of patients. In addition, waiting for molecular test accessibility through the healthcare system, Ki67 together with tumor size and lymph nodal status may be useful to identify ER+ breast cancer patients with adverse prognostic outcome that need combined chemotherapy and hormonal therapy.

Acknowledgments This study was funded by Rete Oncologica Piemonte e Valle d'Aosta (Health Research 2015); LILT_Lega Italiana per Lotta contro i Tumori, local section of Turin (HealthResearch 2014). The funders had no role in study design, data collection and analyses, decision to publish, or preparation of the manuscript.

Author's Contributions Conception and design: SB, SOA, IC, MP, AP; Provision of study materials or patients: SB, PC, MD, MA, FP; Acquisition of data SB, PC, MD, MA, FP; Analysis and interpretation of data SB, SOA, IC. Writing, review, and/or revision of manuscript were performed by all authors.

\section{Compliance with ethical standards}

Conflict of interest The authors declare that they have no conflict of interest.

Open Access This article is distributed under the terms of the Creative Commons Attribution-NonCommercial 4.0 International License (http://creativecommons.org/licenses/by-nc/4.0/), which permits any noncommercial use, distribution, and reproduction in any medium, provided you give appropriate credit to the original author(s) and the source, provide a link to the Creative Commons license, and indicate if changes were made.

\section{References}

1. Coates AS, Winer EP, Goldhirsch A, Gelber RD, Gnant M, Piccart-Gebhart M, Thürlimann B, Senn HJ (2015) Tailoring therapies-improving the management of early breast cancer: St Gallen International Expert Consensus on the Primary Therapy of Early Breast Cancer 2015. Ann Oncol 26:1533-1546. doi:10. 1093/annonc/mdv221

2. Goldhirsch A, Winer EP, Coates AS, Gelber RD, Piccart-Gebhart M, Thürlimann B, Senn HJ (2013) Personalizing the treatment of women with early breast cancer: highlights of the St Gallen International Expert Consensus on the Primary Therapy of Early Breast Cancer. Ann Oncol 24:2206-2223. doi:10.1093/annonc/ mdt 303

3. Goldhirsch A, Wood WC, Coates AS, Gelber RD, Thürlimann B, Senn HJ (2011) Strategies for subtypes-dealing with the diversity of breast cancer: highlights of the St. Gallen International Expert Consensus on the Primary Therapy of Early Breast Cancer 2011. Ann Oncol 22:1736-1747. doi:10.1093/annonc/ mdr304

4. Gerdes J, Li L, Schlueter C, Duchrow M, Wohlenberg C, Gerlach C, Stahmer I, Kloth S, Brandt E, Flad HD (1991) Immunobiochemical and molecular biologic characterization of the cell proliferation-associated nuclear antigen that is defined by monoclonal antibody Ki-67. Am J Pathol 138:867-873

5. Cheang MC, Chia SK, Voduc D, Gao D, Leung S, Snider J, Watson M, Davies S, Bernard PS, Parker JS, Perou CM, Ellis MJ, Nielsen TO (2009) Ki67 index, HER2 status, and prognosis of patients with luminal B breast cancer. J Natl Cancer Inst 101:736-750. doi:10.1093/jnci/djp082

6. Varga Z, Diebold J, Dommann-Scherrer C, Frick H, Kaup D, Noske A, Obermann E, Ohlschlegel C, Padberg B, Rakozy C, Sancho Oliver S, Schobinger-Clement S, Schreiber-Facklam H, Singer G, Tapia C, Wagner U, Mastropasqua MG, Viale G, Lehr HA (2012) How reliable is Ki-67 immunohistochemistry in grade 2 breast carcinomas? A QA study of the Swiss working group of breast-and gynecopathologists. PLoS One 7:e37379. doi:10.1371/ journal.pone.0037379

7. Polley MY, Leung SC, McShane LM, Gao D, Hugh JC, Mastropasqua MG, Viale G, Zabaglo LA, Penault-Llorca F, Bartlett JM, Gown AM, Symmans WF, Piper T, Mehl E, Enos RA, Hayes DF, Dowsett M, Nielsen TO (2013) An international Ki67 reproducibility study. J Natl Cancer Inst 105:1897-1906. doi:10. 1093/jnci/djt306

8. Jonat W, Arnold N (2011) Is the Ki-67 labelling index ready for clinical use? Ann Oncol 22:500-502

9. Gudlaugsson E, Skaland I, Janssen EA, Smaaland R, Shao Z, Malpica A, Voorhorst F, Baak JP (2012) Comparison of the effect of different techniques for measurement of Ki67 proliferation on reproducibility and prognosis prediction accuracy in breast cancer. Histopathology 61:1134-1144. doi:10.1111/j.1365-2559. 2012.04329.x

10. Mikami Y, Ueno T, Yoshimura K, Tsuda H, Kurosumi M, Masuda S, Horii R, Toi M, Sasano H (2013) Interobserver concordance of Ki67 labeling index in breast cancer: Japan Breast Cancer Research Group Ki67 ring study. Cancer Sci 104:1539-1543. doi:10.1111/cas.12245

11. Polley MY, Leung SC, Gao D, Mastropasqua MG, Zabaglo LA, Bartlett JM, McShane LM, Enos RA, Badve SS, Bane AL, Borgquist S, Fineberg S, Lin MG, Gown AM, Grabau D, Gutierrez C, Hugh JC, Moriya T, Ohi Y, Osborne CK, PenaultLlorca FM, Piper T, Porter PL, Sakatani T, Salgado R, Starczynski J, Lænkholm AV, Viale G, Dowsett M, Hayes DF, Nielsen TO (2015) An international study to increase concordance in Ki67 scoring. Mod Pathol 28:778-786. doi:10.1038/ modpathol.2015.38

12. http://www.nccn.org/

13. Denkert C, Loib S, Müller BM, Eidtmann H, Schmitt WD, Eiermann W, Gerber B, Tesch H, Hilfrich J, Huober J, Fehm T, Barinoff J, Jackisch C, Prinzler J, Rüdiger T, Erbstösser E, Blohmer JU, Budczies J, Mehta KM, von Minckwitz G (2013) Ki67 levels as predictive and prognostic parameters in pretherapeutic breast cancer core biopsies: a translational investigation in the neoadjuvant GeparTrio trial. Ann Oncol 24:2786-2793. doi:10.1093/annonc/mdt350 
14. Denkert C, von Minckwitz G (2014) Reply to Ki67 in breast cancer: a useful prognostic marker! Ann Oncol 25:542-543. doi:10.1093/annonc/mdt564

15. Cserni G, Vörös A, Liepniece-Karele I, Bianchi S, Vezzosi V, Grabau D, Sapino A, Castellano I, Regitnig P, Foschini MP, Zolota V, Varga Z, Figueiredo P, Decker T, Focke C, Kulka J, Kaya H, Reiner-Concin A, Amendoeira I, Callagy G, Caffrey E, Wesseling J (2014) Distribution pattern of the Ki67 labelling index in breast cancer and its implications for choosing cut-off values. Breast 23:259-263. doi:10.1016/j.breast.2014.02.003

16. Dowsett M, Nielsen TO, A'Hern R, Bartlett J, Coombes RC, Cuzick J, Ellis M, Henry NL, Hugh JC, Lively T, McShane L, Paik S, Penault-Llorca F, Prudkin L, Regan M, Salter J, Sotiriou C, Smith IE, Viale G, Zujewski JA, Hayes DF (2011) Assessment of Ki67 in breast cancer: recommendations from the International Ki67 in Breast Cancer working group. J Natl Cancer Inst 103:1656-1664. doi:10.1093/jnci/djr393

17. http://www.nordiqc.org/

18. Duffy SW, Tabar L, Vitak B, Warwick J (2006) Tumor size and breast cancer detection: what might be the effect of a less sensitive screening tool than mammography? Breast J 12:S91-S95

19. Verschraegen C, Vinh-Hung V, Cserni G, Gordon R, Royce ME, Vlastos G, Tai P, Storme G (2005) Modeling the effect of tumor size in early breast cancer. Ann Surg 241:309-318
20. Donegan WL (1997) Tumor-related prognostic factors for breast cancer. CA Cancer J Clin 47:28-51

21. Danko ME, Bennett KM, Zhai J, Marks JR, Olson JA Jr (2010) Improved staging in node-positive breast cancer patients using lymph node ratio: results in 1788 patients with long-term followup. J Am Coll Surg 210:797-807. doi:10.1016/j.jamcollsurg. 2010.02.045

22. de Azambuja EL, Cardoso F Jr, de Castro G, Colozza M, Mano MS, Durbecq V, Sotiriou C, Larsimont D, Piccart-Gebhart MJ, Paesmans M (2007) Ki-67 as prognostic marker in early breast cancer: a meta-analysis of published studies involving 12,155 patients. Br J Cancer 96:1504-1513

23. Cianfrocca ML, Goldstein LJ (2004) Prognostic and predictive factors in early-stage breast cancer. Oncologist 9:606-616

24. Schneeweiss A, Chia S, Hickish T, Harvey V, Eniu A, Hegg R, Tausch C, Seo JH, Tsai YF, Ratnayake J, McNally V, Ross G, Cortés J (2013) Pertuzumab plus trastuzumab in combination with standard neoadjuvant anthracycline-containing and anthracycline-free chemotherapy regimens in patients with HER2positive early breast cancer: a randomized phase II cardiac safety study (TRYPHAENA). Ann Oncol 24:2278-2284. doi:10.1093/ annonc/mdt182 